\title{
Anti-idiotypic Antibodies against a Human Multiple Organ-reactive Autoantibody Detection of Idiotopes in Normal Individuals and Patients with Autoimmune Diseases
}

Karim Essani, Jo Satoh, Bellur S. Prabhakar, Patrick R. McClintock, and Abner Louis Notkins

Laboratory of Oral Medicine, National Institute of Dental Research, National Institutes of Health, Bethesda, Maryland 20205

\begin{abstract}
We have recently isolated and characterized a human monoclonal autoantibody, MOR-h1 (multiple organ-reactive human 1), that reacts with antigens in multiple organs and have shown that this antibody binds to human growth hormone and a 35,000-mol wt protein. In the present study we generated three monoclonal antiidiotypic antibodies (4E6, 3E5, and 3F6) against MOR-h1. These anti-idiotypic antibodies specifically reacted with MOR-h1 and not with 26 other multiple organ-reactive monoclonal IgM autoantibodies nor with pooled human IgM (myeloma proteins). The binding of the anti-idiotypic antibodies to MOR-h1 was inhibited by both human growth hormone and the 35,000-mol wt protein, which strongly suggests that these antibodies react with epitopes at or near the paratope on MOR-h1. The results of competitive binding experiments revealed that the epitope recognized by $4 \mathrm{E6}$ is distinct from that recognized by $3 E 5$ and 3F6. Using these anti-idiotypic antibodies, lymphocytes and sera from normal individuals were tested for the presence of the 4E6 and 3E5/3F6 idiotopes. By indirect immunofluorescence, the 4E6 idiotope was detected on an average of $1.1 \%$ of normal circulating B lymphocytes, and by enzyme-linked immunosorbent assays, the 4 E6 and to a lesser extent the 3E5/3F6 idiotopes were found on IgG molecules in sera of normal individuals. In spite of the expression of idiotopes known to be present on MOR-h1, no MOR-h1-like antibody activity was detected in normal sera. Examination of sera from patients with several autoimmune diseases failed to show an increased expression of the 4E6 idiotope as compared with normal controls. These data suggest that antiidiotypic antibody $4 \mathrm{E} 6$ recognizes a public idiotope, the expression of which is not restricted to autoimmune disease.
\end{abstract}

\section{Introduction}

Idiotypic determinants on antibodies and cells and their recognition by anti-idiotypic antibodies have been given a prominent role in current theories of immunoregulation (1-4). The idiotopes expressed on autoantibodies are of particular interest since it has been suggested that autoantibodies may represent failures of, or gaps in, the immunoregulatory network. Recent studies in mice (5) and in humans (6) suggested that certain idiotypes are closely associated with particular autoimmune disorders. It also has been speculated that a limited number of families of immunoglobulins may be involved in autoimmunity

Dr. Satoh's present address is The Third Department of Internal Medicine, Tohoku University School of Medicine, 1-1 Seiryo-machi, Sendai, Miyagi 980, Japan.

Received for publication 25 February 1985.

The Journal of Clinical Investigation, Inc.

Volume 76, October 1985, 1649-1656
(7). If this turns out to be the case, then anti-idiotypic antibodies may serve as useful probes to quantitate the level of expression of idiotopes in both normal individuals and patients.

Recently we prepared a hybridoma secreting a human monoclonal autoantibody, designated MOR-h 1 (multiple organreactive human 1$)^{1}(8)$. This antibody (IgM- $\kappa$ ) reacts with antigens in several different organs including the pituitary, thyroid, pancreas, and stomach. Using an MOR-h 1 immunoaffinity column we have isolated the autoantigens (i.e., 35,000 and 21,000-mol wt proteins) with which this autoantibody reacts. The $35,000-$ mol $w t$ protein is present in the pituitary, thyroid, and stomach; and the $21,000-\mathrm{mol}$ wt protein, which was shown to be human growth hormone (hGH), is found only in the pituitary. We now report the preparation and characterization of three monoclonal antibodies directed against idiotypic determinants at or near the paratope of MOR-hl. Using these anti-idiotypic antibodies we have studied the expression of the corresponding idiotopes on immunoglobulins in the sera of normal individuals and patients with autoimmune diseases.

\section{Methods}

Human monoclonal autoantibodies. The procedure for the preparation of MOR-h1 and 26 other human monoclonal multiple organ-reactive (MOR) antibodies has already been described (8-9). All of these autoantibodies are of the IgM class. Some of these antibodies were prepared by fusing human peripheral $B$ lymphocytes with either human or mouse myeloma cells (8). Others were prepared by immortalizing peripheral B lymphocytes with Epstein-Barr virus (9).

Purification of MOR-hl. MOR-hl was purified using an immunoaffinity column, which was prepared by coupling the IgG fraction of sheep anti-human IgM to CNBr-activated Sepharose-4B (Pharmacia Fine Chemicals, Piscataway, NJ) as previously described (10). The adsorbed MOR-hl was eluted with $0.1 \mathrm{M}$ glycine- $\mathrm{HCl}(\mathrm{pH} 2.5)$; the $\mathrm{pH}$ of the eluate was adjusted to 7.5 before exhaustive dialysis against deionized water, and the material was lyophilized. The purity of MOR-hl was tested by SDS-polyacrylamide gel electrophoresis, and only two bands having the apparent molecular weights of $\mu$ - and $\kappa$-chains were detected. The purified MOR-hl was also checked for immunological reactivity with synthetic hGH (kindly provided by Genentech, Inc., South San Francisco, CA) and a 35,000-mol wt polypeptide (from human gastric mucosa) by employing an enzyme-linked immunosorbent assay (ELISA) as described earlier (10).

Preparation, screening, and purification of monoclonal anti-idiotypic antibodies. Balb/c AnN mice received five weekly, intraperitoneal injections of $100 \mu \mathrm{g}$ of affinity-purified MOR-hl. $3 \mathrm{~d}$ after the last injection, splenic lymphocytes were fused with $\mathrm{P}_{3} 653 \mathrm{Ag} 8$ myeloma cells using

1. Abbreviations used in this paper: ELISA, enzyme-linked immunosorbent assay; FITC, fluorescein isothiocyanate; hGH, human growth hormone; IDDM, insulin-dependent diabetes mellitus; MOR, multiple organ-reactive; MOR-h1, multiple organ-reactive human 1 autoantibody; RIA, radioimmunoassay; SLE, systemic lupus erythematosus; TRITC, tetramethylrhodamine isothiocyanate. 
$50 \%$ polyethylene glycol at neutral $\mathrm{pH}$, essentially as described by Köhler and Milstein (11). The fused cells were plated in 96-well tissue culture plates and incubated at $37^{\circ} \mathrm{C}$. Supernatants from cultures grown to confluency were initially screened for anti-MOR-hl and anti-human IgM antibody by ELISA in which Immulon II plates (Dynatech Laboratories, Alexandria, VA) were coated with either MOR-hl or pooled human myeloma IgM. The bound monoclonal IgG was detected using peroxidase-labeled goat anti-mouse $\gamma$-chain-specific antibodies. The positive wells showing reactivity with MOR-h1, but not with pooled human IgM, were cloned using the end point dilution method (12). The three hybridomas thus obtained were designated $4 \mathrm{E} 6,3 \mathrm{E} 5$, and $3 \mathrm{~F} 6$.

Immunoreagents. All antiimmunoglobulin reagents, including peroxidase conjugates and fluorescently labeled immunoglobulins or fragments, and pooled human myeloma IgM were obtained from Cooper Biomedical, Malvern, PA.

ELISA. Except where indicated, the following general procedures for ELISA were used. Affinity-purified antigens or antibodies $(1 \mu \mathrm{g} /$ well $)$ were coated on Immulon II plates (Dynatech Laboratories) in carbonatebicarbonate buffer ( $\mathrm{pH} 9.6$ ) overnight at $4^{\circ} \mathrm{C}$. In some experiments, MOR$\mathrm{hl}$ from hybridoma medium was bound to plates previously coated with anti-human IgM ( $\mu$-chain-specific) to selectively retain MOR-h1 on the Immulon II wells. Duplicate test samples were diluted in phosphatebuffered saline (PBS) containing $0.1 \%$ gelatin and $0.05 \%$ Tween 20 , and the plates were incubated with samples for $2 \mathrm{~h}$ at room temperature. At each step and after the final incubation, the plates were washed six times with PBS containing 0.05\% Tween 20 (PBS-Tween). Peroxidase-conjugated antibodies diluted 1:300 with PBS containing $0.1 \%$ gelatin were used to detect antigens or antibodies. Peroxidase activity was measured using $\mathrm{H}_{2} \mathrm{O}_{2}$ and ortho-phenylenediamine, and the optical density (OD) at $492 \mathrm{~nm}$ was read with a microplate reader (Flow Laboratories, McLean, VA).

Radioiodination of antibodies and solid-phase radioimmunoassays (RIAs). Affinity-purified monoclonal antibodies were iodinated by a modification of the chloramine $T$ method (13). The reaction mixture was then chromatographed on a Sephadex G-25M column (Pharmacia Fine Chemicals) to separate the protein from free radioiodine. The iodinated proteins were then dialyzed overnight against $\mathrm{PBS}$ at $4^{\circ} \mathrm{C}$, and were tested for their immunological reactivity in a solid-phase RIA. At least $90 \%$ of the input counts per minute (cpm) bound to MOR-h1, while only 3-5\% of the input cpm reacted with gelatin-coated wells which served as the negative control.

For competitive binding experiments Immulon II removawell strips (Dynatech Laboratories) were coated with $1 \mu \mathrm{g} /$ well of affinity-purified MOR-h1 as described for ELISA. Following washing, $0.1 \%$ gelatin in PBS was added to each well, and incubated for $2 \mathrm{~h}$ at room temperature to block the remaining protein binding sites on the wells. Serial twofold dilutions of each monoclonal anti-idiotypic antibody (initial concentration, $1 \mathrm{mg} / \mathrm{ml}$ ) were made in PBS containing $0.1 \%$ gelatin. To each of these dilutions ${ }^{125}$ I-anti-idiotypic antibody was added. An aliquot of the mixture of labeled and unlabeled monoclonal antibodies $(50 \mu \mathrm{l})$ was then added to wells coated with MOR-hl. Following $2 \mathrm{hr}$ of incubation at $37^{\circ} \mathrm{C}$, the wells were washed six times with PBS-Tween and the radioactivity was measured in a Biogamma II counter (Beckman Instruments, Inc., Fullerton, CA). Percent inhibition was computed as 100 times the cpm bound in the presence of inhibitor divided by the cpm bound in the absence of inhibitor.

Detection of $4 E 6$ idiotope-bearing $B$ lymphocytes in the peripheral blood. Mononuclear cells were separated from heparinized human blood by density centrifugation, and the B lymphocyte-enriched population was obtained after depletion of the T lymphocytes by rosetting with 2aminoethylisothiouronium bromide hydrobromide-treated sheep erythrocytes (14). The cells thus obtained were washed with cold PBS containing $0.1 \%$ bovine serum albumin (BSA) and $0.01 \%$ sodium azide. The cells $\left(1 \times 10^{6}\right.$ cells $)$ were resuspended in $0.2 \mathrm{ml}(25 \mu \mathrm{g} / \mathrm{ml})$ of either 4E6 or an $\operatorname{IgG}_{1}(\kappa)$ mouse myeloma (MOPC-21) and incubated for $30 \mathrm{~min}$ on ice. After washing in PBS the cells were reacted with a mixture of tetramethylrhodamine isothiocyanate (TRITC)-conjugated $\mathrm{F}\left(\mathrm{ab}^{\prime}\right)_{2}$ fragment of goat anti-human immunoglobulins (IgA + IgG + IgM) and fluorescein isothiocyanate (FITC)-conjugated $F\left(a^{\prime}\right)_{2}$ fragment of sheep anti-mouse IgG (that did not cross react with human IgG) for $30 \mathrm{~min}$ on ice. The cells were washed and fixed with $1 \%$ paraformaldehyde in PBS overnight at $4^{\circ} \mathrm{C}$, and then viewed with an epifluorescence microscope. The cells stained with TRITC (i.e., surface Ig-positive B lymphocytes) or the cells stained with both TRITC and FITC (i.e., 4E6-reacting B lymphocytes) were counted under rhodamine and fluorescein filters, respectively. At least 500 surface Ig-positive cells were counted, and the percentage of 4E6-reacting B lymphocytes out of the total B lymphocytes was calculated. Neither MOPC-21 nor the FITC-labeled sheep anti-mouse IgG by itself stained B lymphocytes.

Detection by ELISA of $4 E 6,3 E 5$, and $3 F 6$ idiotopes in human sera. Human sera diluted to 1:10 with PBS containing 2\% BSA and $0.05 \%$ Tween-20 were added to wells that had been coated with $1 \mu \mathrm{g} /$ well of affinity-purified 4E6, 3E5, 3F6, or MOPC-21, and the plates were incubated overnight at $4^{\circ} \mathrm{C}$. After washing, the plates were incubated for $5 \mathrm{~h}$ at room temperature or overnight at $4^{\circ} \mathrm{C}$ with peroxidase-conjugated goat anti-human IgG ( $\gamma$-chain-specific) previously absorbed with both MOPC-21 and the appropriate anti-idiotypic antibody. After washing the substrate was added and the $\mathrm{OD}_{492}$ of each sample was measured. Pilot experiments with peroxidase-conjugated goat anti-human IgM ( $\mu$ chain-specific) yielded high background activity preventing its use to reliably detect the 4E6, 3E5, and 3F6 idiotopes on human IgM in sera.

\section{Results}

Preparation of monoclonal anti-idiotypic antibodies against MOR-hl and their reactivities with human monoclonal antibodies. Hybridomas secreting anti-idiotypic antibodies were prepared by fusing spleen cells from MOR-hl-immunized BALB/c mice with $P_{3} 653 \mathrm{Ag} 8$ myeloma cells. Two independent fusions ( 480 wells each) yielded a total of seven wells that reacted with MOR-h1. After further testing and cloning, three of these (designated 4E6, 3E5, and 3F6) were found to react specifically with MOR-h1 and not with pooled human IgM. All three were of the $\operatorname{IgG}_{1}(\kappa)$ type. To assess the specificity of these anti-idiotypic antibodies, ELISA plates coated with 27 different human monoclonal IgM autoantibodies were incubated with 4E6, 3E5, and 3F6. All of the monoclonal anti-idiotypic antibodies reacted strongly with MOR-h1 but gave negligible reactions with the other 26 monoclonal IgMs and with pooled human myeloma IgM (Fig. 1).

The preceding experiment showed that our mouse monoclonal IgG anti-idiotypic antibodies reacted specifically with MOR-h1. The formal possibility existed, however, that MORhl had an affinity for mouse IgG. To test this possibility MORh1 was incubated with several mouse monoclonal IgGs including the anti-idiotypic antibody, 4E6 (Table I). MOR-h1 reacted strongly with 4E6, but did not react with any of the other mouse monoclonal IgGs.

Inhibition of binding of MOR-h1 to anti-idiotypic antibodies by $h G H$ and 35,000-mol wt protein. MOR-h1 has been shown to react with both hGH and a 35,000-mol wt protein found in various human tissues (10). If our anti-idiotypic antibodies are directed against a site at or near the paratope of MOR-h1, then hGH and the 35,000-mol wt protein should inhibit the binding of MOR-h 1 to the anti-idiotypic antibodies. Fig. $2 A$ shows that incubation of MOR-hl with hGH or 35,000-mol wt protein inhibited its binding to 4E6-coated plates. The degree of inhibition was related to the concentration of the ligands. These data also suggest, but do not prove, that the affinity of MOR-h1 for hGH is less than its affinity for the $35,000-$ mol wt protein. BSA used as a control showed no reactivity except at very high concentrations. Similar results were obtained when a second mono- 


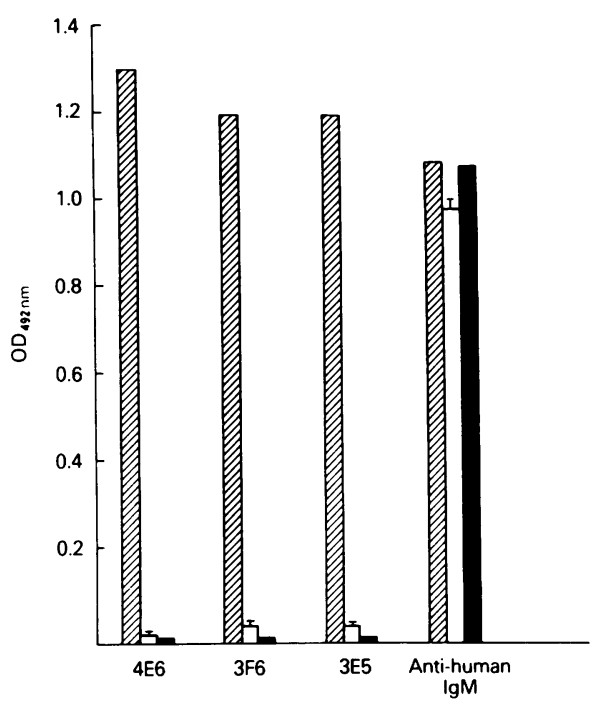

Figure 1. Reactivities of monoclonal anti-idiotypic antibodies with MOR-h1 and other monoclonal human IgMs. Duplicate wells in an ELISA plate were coated with 27 human monoclonal IgMs including MOR-hl or pooled human myeloma IgM as described in Methods. The plates were washed and then incubated with anti-idiotypic antibodies. (回) MOR-h l, (ㅁ) mean of 26 human MOR antibodies, ( $\square$ ) pooled human myeloma IgM. Bar shows 1 SD. Because variations in the amount of human IgM bound to the wells might cause variability in the reactions with the anti-idiotypic antibodies, the reaction of peroxidase-conjugated anti-human IgM ( $\mu$-chain-specific) was used to confirm that all wells contained approximately equal amounts of IgM.

clonal anti-idiotypic antibody, 3F6, was used (Fig. 2 B). In this case, hGH and the 35,000-mol wt protein inhibited the binding of MOR-h1 to 3F6 over an even greater range of ligand con-

Table I. Interaction of MOR-hl with Mouse Monoclonal Anti-idiotypic Antibody and Other Monoclonal Mouse IgGs*

\begin{tabular}{llll}
\hline & & \multicolumn{2}{l}{$\mathrm{OD}_{492}\left(\times 10^{3}\right)$} \\
\cline { 3 - 4 } Antibodies & Isotype§ & MOR-h1 & Anti-mouse IgG" \\
\hline 4E6 & IgG1 & 797 & 870 \\
$183-4$ & IgG1 & 42 & 670 \\
$187-1$ & IgG2a & 3 & 894 \\
$204-4$ & IgG2a & 5 & 853 \\
$356-1$ & IgG2a & 20 & 850 \\
$286-1$ & IgG2b & 30 & 782 \\
$9-4$ & IgG3 & 48 & 754 \\
PBS & - & 25 & 11 \\
\hline
\end{tabular}

* ELISA plates were coated with the IgG fraction of sheep anti-mouse IgG, $0.1 \mathrm{ml}$ of the culture supernatant from each mouse hybridoma was added to duplicate wells, and the plates were incubated to fix the monoclonal IgG onto the plates. After washing, $0.1 \mathrm{ml}$ of MOR-hl culture supernatant was added and the MOR-hl bound to mouse IgG was detected by peroxidase-conjugated goat anti-human IgM ( $\mu$-chainspecific).

‡ Except 4E6, all others were anti-Coxsackie B4 monoclonal antibodies (15).

$\S$ Isotype was determined by immunodiffusion with specific typing sera.

"The reaction of peroxidase-conjugated anti-mouse IgG ( $\gamma$-chain-specific) with the antibody-coated plates was used to show that all of the mouse monoclonal IgGs were present in the wells in approximately equal amounts.

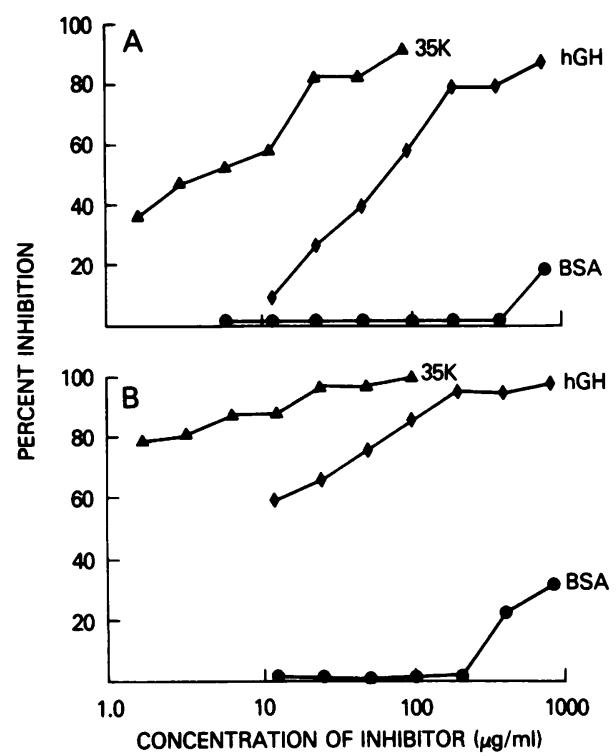

Figure 2. Inhibition of binding of MOR-h1 to anti-idiotypic antibodies by hGH and 35,000-mol wt protein as measured by ELISA. Culture supernatant containing $2 \mu \mathrm{g} / \mathrm{ml}$ of MOR-hl was mixed with vary-

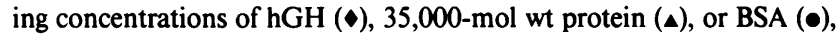
and incubated overnight at $4^{\circ} \mathrm{C}$. The mixtures were then added to ELISA plates coated with affinity-purified anti-idiotypic antibodies 4E6 $(A)$ or 3F6 $(B)$. Binding of MOR-h1 to the anti-idiotypic antibodies was detected using peroxidase-conjugated goat anti-human IgM ( $\mu$ chain-specific). Maximum binding (100\%) corresponded to $\sim 1,200 \mathrm{OD}_{492}\left(\times 10^{3}\right)$ and nonspecific binding $(0 \%)$ was always $<100$ $\mathrm{OD}_{492}\left(\times 10^{3}\right)$.

centrations. Taken together, these experiments show that both 4E6 and 3F6 are ligand-inhibitable.

Evidence for ligand inhibition was also obtained in a solidphase RIA in which the order of adding the reagents was reversed. Plates were coated with MOR-h1, incubated with varying concentrations of $\mathrm{hGH}$, and then the binding of ${ }^{125}$ I-labeled 4E6, $3 \mathrm{~F} 6$, and polyclonal anti-human IgM was measured. As seen in Fig. 3 the binding of the anti-idiotypic antibodies, but not polyclonal anti-human IgM was inhibited.

Inhibition of binding of $h G H$ to $M O R-h l$ by anti-idiotypic

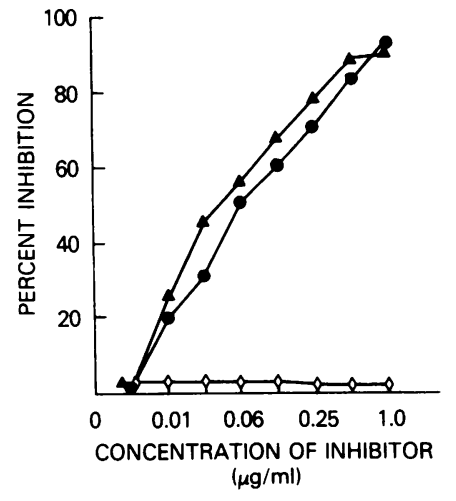

Figure 3. Inhibition of binding of anti-idiotypic antibodies to MOR-hl by hGH as measured by RIA. Immulon II wells were coated with affinity-purified MOR-hl, and various concentrations of purified $\mathrm{hGH}$ in PBS containing $0.1 \%$ gelatin were added to duplicate wells and incubated at $4^{\circ} \mathrm{C}$ overnight. The wells were washed and ${ }^{125} \mathrm{I}-4 \mathrm{E} 6(\bullet),{ }^{125} \mathrm{I}-3 \mathrm{~F} 6(\Delta)$, or ${ }^{125}$ I polyclonal anti-human $\operatorname{IgM}(\diamond)$ was added and incubated at $37^{\circ} \mathrm{C}$ for $2 \mathrm{~h}$. Following extensive washing, radioactivity was measured. Maximum binding (100\%) corresponded to $\sim 6,000 \mathrm{cpm}$ and nonspecific binding $(0 \%)$ was always $<175 \mathrm{cpm}$. 


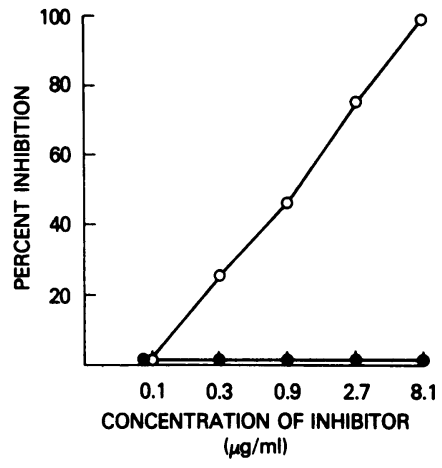
well and incubated as described in Methods. After washing, $0.1 \mathrm{ml}$ of rabbit anti-hGH serum (kindly provided by the National Pituitary Agency, Baltimore, MD) diluted 1:2,000 was added to each well. Rabbit IgG binding to $\mathrm{hGH}$ was detected by peroxidase-conjugated goat anti-rabbit IgG and the percent inhibition of hGH-binding was then calculated. Maximum binding $(100 \%)$ corresponded to $\sim 1,600 \mathrm{OD}_{492}$ $\left(\times 10^{4}\right)$ and nonspecific binding $(0 \%)$ was always $<50 \mathrm{OD}_{492}\left(\times 10^{4}\right)$.

antibody 4E6. If $4 \mathrm{E} 6$ is specific for an epitope located at the antigen binding site on MOR-hl, then the binding of hGH to MOR-h1 should be inhibitable by the anti-idiotypic antibody. Fig. 4 shows that 4E6 blocks the binding of hGH to MOR-h1, whereas a control mouse monoclonal IgG antibody had no effect. Together with data from Figs. 2 and 3, these results show that anti-idiotypic antibody $4 \mathrm{E} 6$ is directed against a site at or near the paratope on MOR-h1.

Monoclonal anti-idiotypic antibodies recognize different epitopes on MOR-hl. The possibility that the different anti-idiotypic antibodies might be recognizing different epitopes was evaluated in blocking experiments. As shown in Fig. $5 \mathrm{~A}$, the binding of ${ }^{125}$ I-labeled 4E6 to MOR-h1 was inhibited by unlabeled 4E6, but not by $3 \mathrm{E} 5$ or $3 \mathrm{~F} 6$. In contrast, the binding of ${ }^{125}$ I-labeled $3 \mathrm{E} 5$ and ${ }^{125}$-labeled $3 \mathrm{~F} 6$ to MOR-h 1 was inhibited by both 3E5 and 3F6, but not by $4 \mathrm{E} 6$ (Fig. $5 B$ and $C$, respectively). Thus antibody 4E6 recognizes an epitope on MOR-h1 that is different from that recognized by $3 \mathrm{E} 5$ and $3 \mathrm{~F} 6$, whereas $3 \mathrm{E} 5$ and $3 \mathrm{~F} 6$ appear to be recognizing the same epitope on the MOR-h1 molecule.

Detection of $4 E 6$ idiotope-bearing B lymphocytes in peripheral blood. Having characterized the monoclonal anti-idiotypic antibodies, we wanted to see if the idiotopes with which they reacted were present on immunoglobulin-bearing B cells. Peripheral blood $B$ lymphocytes were examined for the presence of 4E6 idiotope-bearing $B$ cells by indirect immunofluorescence with anti-idiotypic antibody 4E6. From each individual at least 500 surface immunoglobulin-bearing cells were counted. In 13 out of 14 individuals (Table II), between 0.2 and $3.0 \%$ of the B lymphocytes expressed the 4E6 idiotope. Neither MOPC-21 nor sheep anti-mouse IgG stained any of the human B cells.

Detection of 4E6 idiotope-bearing immunoglobulins in human sera. Since up to $3 \%$ of B cells from normal individuals were found to bear the 4E6 idiotope, sera from normal individuals were tested for the presence of this idiotope. Fig. 6 shows that close to $85 \%$ of 130 human sera reacted with anti-idiotypic antibody 4E6 (i.e., 2 SD above control). Considerable quantitative differences, however, were found among individuals. In the same individual, expression of the 4E6 idiotope remained fairly constant with time (Fig. 7).

Comparison of the expression of $4 E 6$ and $3 E 5 / 3 F 6$ idiotopes in human sera. The presence of the 4E6 idiotope in human sera raised the question as to whether the 3E5 and 3F6 idiotopes also were expressed. Plates were coated with equal concentrations ( 1 $\mu \mathrm{g} /$ well) of the anti-idiotypic antibodies (4E6, 3E5, and 3F6) and then incubated with MOR-hl or a panel of normal human sera. As seen in Fig. 8, MOR-h1 reacted to approximately the same extent with all three anti-idiotypic antibodies. The panel of human sera also reacted with anti-idiotypic antibodies 3E5 and 3F6, but to a much lesser extent than with 4E6. One possible explanation for the differences in reactivity is that the 4E6 idiotope may be present on molecules that do not always possess the 3E5 and 3F6 idiotopes.

Sera positive for the $4 E 6$ idiotope do not react with $h G H$, 35,000-mol wt protein, or human tissues. The widespread expression of the 4E6 idiotope suggested that at least some sera might contain immunoglobulins bearing paratopes similar in reactivity to MOR-hl. Five sera that showed different degrees of expression of the 4E6 idiotope were tested for their ability to react with $\mathrm{hGH}$, the 35,000-mol wt protein, and sections of normal human tissues. As seen in Table III, none of the sera showed appreciable reactivity with any of the antigens tested. In addition, we tested the ability of different concentrations (from $1 \mu \mathrm{g}$ to 1 $\mathrm{mg} / \mathrm{ml}$ ) of hGH to inhibit the binding of these sera to 4E6coated wells in a competitive inhibition assay. hGH inhibited the binding of MOR-h1 to 4E6 in a concentration-dependent manner, but failed to significantly inhibit the binding of these sera to 4E6 (results not shown).

Expression of the $4 E 6$ idiotope in patients with autoimmune disorders. Because the MOR-hl hybridoma was originally prepared from the lymphocytes of a patient with insulin-dependent diabetes mellitus (IDDM) and because MOR-hl reacts with autoantigens, we wanted to see if the 4E6 idiotope might be expressed to a greater extent in sera from patients with autoimmune diseases than in sera from normal individuals. Serum or plasma was obtained from 85 normal individuals, 24 patients with IDDM, 41 patients with IDDM and Hashimoto's thyroiditis, 49

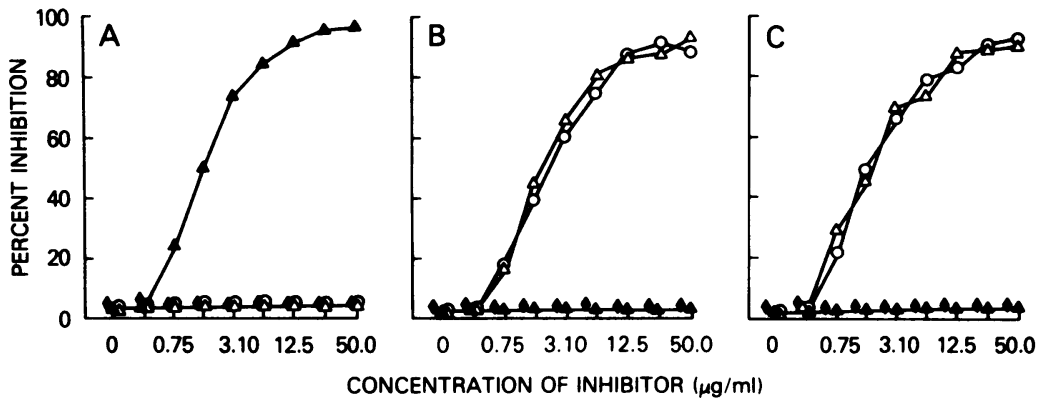

Figure 5. Monoclonal anti-idiotypic antibodies recognize different epitopes on MOR-hl. Immulon II plates were coated with affinity-purified MOR-h1 $(1 \mu \mathrm{g} /$ well $)$. Various concentrations of unlabeled inhibitors, 4E6 $(\Delta), 3 E 5(\Delta), 3$ F6 (0), or 356-1 (४) were mixed with ${ }^{125} \mathrm{I}-4 \mathrm{E} 6(A),{ }^{125} \mathrm{I}-3 \mathrm{~F} 6(B)$ or ${ }^{125} \mathrm{I}-3 \mathrm{E} 5(C)$. The mixtures were added to the MOR-hl-coated wells in duplicate. The plates were incubated for $2 \mathrm{hr}$ at $37^{\circ} \mathrm{C}$ and washed extensively; the radioactivity was measured and percent inhibition calculated. Maximum binding (100\%) corresponded to $\sim 6,500 \mathrm{cpm}$ and nonspecific binding $(0 \%)$ was always $<150 \mathrm{cpm}$. 
Table II. Frequency of 4 E6 Idiotope-bearing B Lymphocytes in Peripheral Blood Detected by Anti-idiotypic (4E6) Antibody*

\begin{tabular}{ll}
\hline Individual & $\begin{array}{l}\text { Percent 4E6 idiotope-bearing } \\
\text { B lymphocytesł }\end{array}$ \\
\hline 1 & 0 \\
2 & 0.2 \\
3 & 0.2 \\
4 & 0.4 \\
5 & 0.5 \\
6 & 0.7 \\
7 & 0.8 \\
8 & 1.0 \\
9 & 1.2 \\
10 & 1.5 \\
11 & 1.6 \\
12 & 2.0 \\
13 & 2.8 \\
14 & 3.0 \\
Average & 1.1 \\
\hline
\end{tabular}

* Determined by indirect immunofluorescence as described in Methods.

$\ddagger$ At least 500 surface immunoglobin-bearing cells were counted in each sample.

patients with only Hashimoto's thyroiditis, and 47 patients with rheumatological disorders (predominantly systemic lupus erythematosus, SLE). As shown in Fig. 9, except for a few unusually high values for sera from patients with both IDDM and thyroiditis, no discernible differences were detected among the groups of sera.

\section{Discussion}

We have generated three murine monoclonal anti-idiotypic antibodies against a human monoclonal autoantibody (MOR-h1) that reacts with multiple organs $(8,10)$. It is generally accepted that an anti-idiotypic antibody is directed against the paratope if it is ligand-inhibitable $(16,17)$. Our anti-idiotypic antibodies reacted specifically with MOR-h1, but not with 26 other mono-

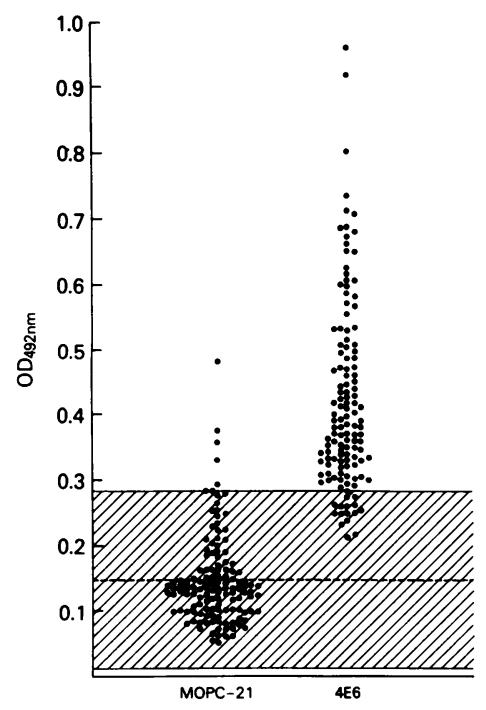

Figure 6. Detection of 4E6 idiotope in human sera. Binding of 130 human sera to wells coated with either anti-idiotypic antibody $4 \mathrm{E} 6$ or MOPC-21 (control) was determined in an ELISA using peroxidase-conjugated goat anti-human IgG as described in Methods. Each point represents an individual serum. The shaded area represents the mean \pm 2 SD of the MOPC-21 control values.

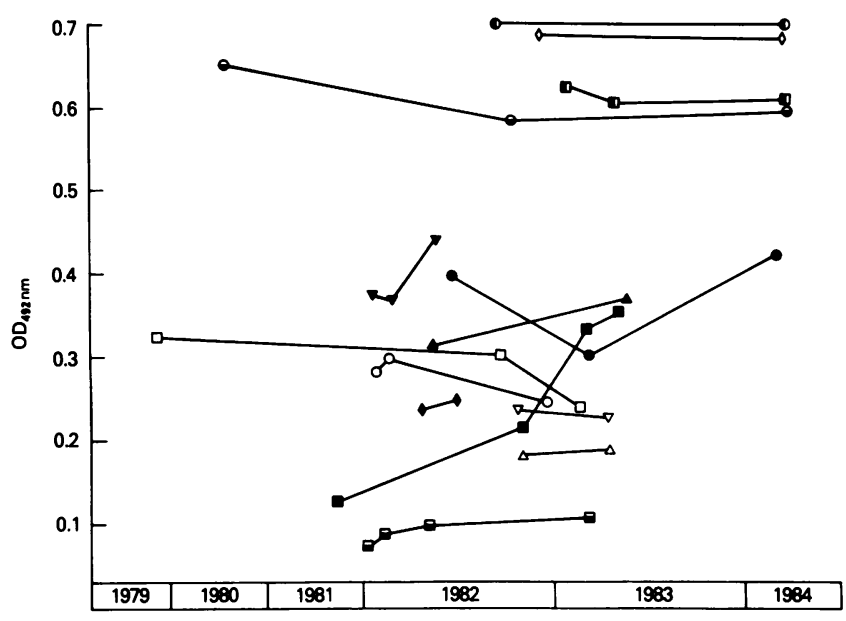

Figure 7. Detection of the 4E6 idiotope in serial bleedings from the same individuals. Serum samples collected from the same individuals over a period of time were tested for reactivity with 4E6-coated plates in an ELISA as described in Methods. Each symbol represents a different individual.

clonal MOR autoantibodies nor with pooled human myeloma IgM. Blocking experiments clearly demonstrated that the interaction of purified $\mathrm{hGH}$ and the $35,000-\mathrm{mol}$ wt protein with

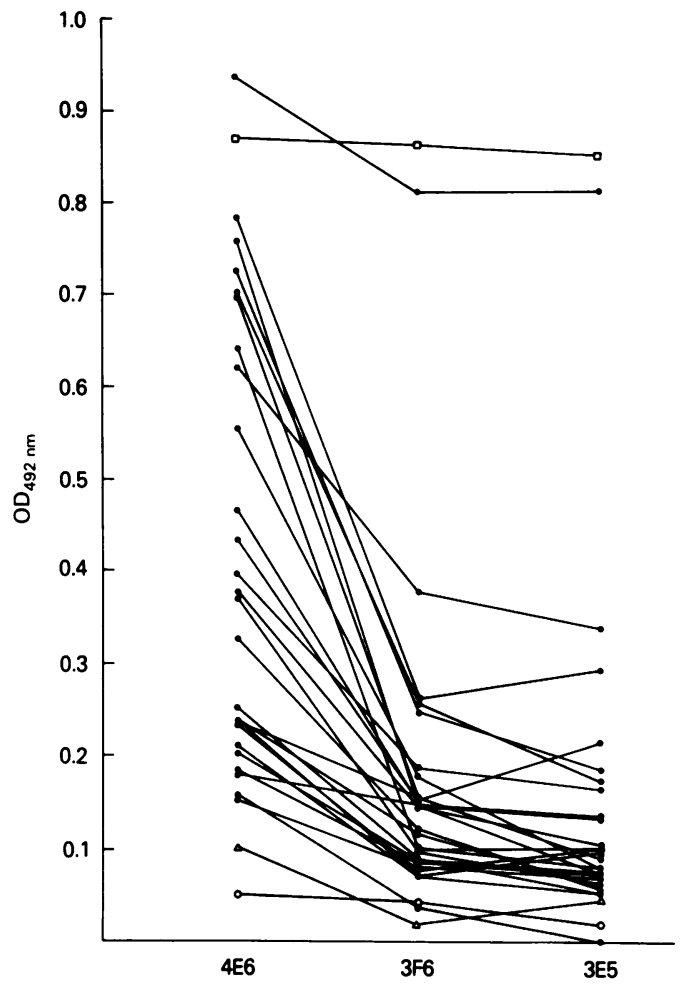

Figure 8. Detection of 4E6, 3E5, and 3F6 idiotopes in human sera. Serum samples were incubated in wells coated with $4 \mathrm{E} 6$ or $3 \mathrm{E} 5$ or $3 \mathrm{~F} 6$ anti-idiotypic antibody, and the binding of human immunoglobulin was determined in an ELISA using peroxidase-conjugated goat antihuman IgG as described in Methods. Each serum was also reacted with a MOPC-21-coated control well, and the value plotted for each serum was calculated by subtracting the OD of the respective MOPC21 well from the OD of the well containing the corresponding antiidiotypic antibody. MOR-hl binding was detected using peroxidaseconjugated goat anti-human IgM ( $\mu$-chain-specific). (๑), individual human sera; ( (), MOR-h 1; (O), PBS; $(\Delta)$, pooled human IgG. 
Table III. Reactivity of Sera Expressing the 4E6 Idiotope with hGH, the 35,000-mol wt Protein, and Normal Tissues

\begin{tabular}{|c|c|c|c|c|c|}
\hline \multirow[b]{2}{*}{ Sera } & \multirow[b]{2}{*}{$\begin{array}{l}\text { Reactivity of } \\
\text { sera with } 4 \mathrm{E} 6^{*}\end{array}$} & \multicolumn{4}{|c|}{ Reactivity of sera with: } \\
\hline & & PBS $^{*}$ & $\mathrm{hGH}^{*}$ & $\begin{array}{l}35,000-\text { mol wt } \\
\text { protein* }\end{array}$ & Tissuesł \\
\hline No. 80 & $46 \S$ & 42 & 85 & 82 & - \\
\hline No. 67 & 122 & 39 & 89 & 72 & - \\
\hline No. 32 & 214 & 49 & 96 & 99 & - \\
\hline No. 95 & 594 & 22 & 44 & 42 & - \\
\hline No. 55 & 692 & 175 & 185 & 176 & - \\
\hline PBS & 61 & 82 & 111 & 108 & - \\
\hline MOR-h1 & 1,026 & 71 & 516 & 1,099 & ++ \\
\hline
\end{tabular}

* Plates were coated with $1 \mu \mathrm{g}$ of 4E6, $1 \mu \mathrm{g} \mathrm{hGH}, 0.5 \mu \mathrm{g}$ of 35,000mol wt protein per well, or PBS without protein (PBS). Sera were diluted 1:5 (MOR-hl was used at $26 \mu \mathrm{g} / \mathrm{ml}$ ) in PBS, added to the coated wells, and incubated and washed as described in Methods. The bound immunoglobulins were then detected by peroxidase-conjugated antihuman immunoglobulins $(\operatorname{IgA}+\operatorname{IgG}+\operatorname{IgM})$ or anti-human IgM $(\mu-$ chain-specific), respectively.

$¥$ Sera were screened on sections of human thyroid, pituitary, stomach, and pancreas by indirect immunofluorescence using FITC-conjugated anti-human immunoglobulins (IgA + IgG $+\operatorname{IgM})$ as described previously.

$\S \mathrm{OD}_{492}\left(\times 10^{3}\right)$

MOR-hl inhibited the binding of MOR-hl to the anti-idiotypic antibodies, and conversely, the interaction of anti-idiotypic antibody 4E6 with MOR-h1 inhibited the binding of hGH to MORh1. We have also shown that both hGH and the 35,000-mol wt protein can compete with anti-idiotypic antibodies for binding to MOR-hl in a concentration-dependent manner. These experiments provide compelling evidence that the anti-idiotypic antibodies are reacting specifically either with the paratope or with an epitope very close to the paratope on MOR-h 1 .

Based on competitive binding experiments, our monoclonal anti-idiotypic antibodies appear to recognize two different idiotopes on MOR-h1 (Fig. 5). Antibody 4E6 defines an idiotypic determinant on MOR-h1 which is clearly distinct from the site(s) recognized by antibodies 3E5 and 3F6. Since antibodies 3E5 and 3F6 compete with each other, it appears that they may be recognizing the same idiotope which we have designated the 3E5/3F6 idiotope. On immunoglobulin molecules in human sera, in contrast to MOR-h1, the 4E6 idiotope appears to be expressed independently of the 3E5/3F6 idiotope (Fig. 8).

Other experiments were carried out in an attempt to further characterize the anti-idiotypic antibodies. Since monoclonal autoantibody MOR-h1 (idiotypic antibody-Abl) reacts with hGH and since some anti-idiotypic antibodies (Ab2) are internal images of the paratope with which they react (18-21), we tested anti-idiotypic antibody 4E6 for its ability to bind to hGH receptors. Even at a high concentration, antibody $4 \mathrm{E} 6(1 \mathrm{mg} / \mathrm{ml})$ failed to inhibit the binding of growth hormone to its receptor on IM-9 cells (K. Essani, unpublished observations) (22). Others have shown that immunization with "internal image" anti-idiotypic antibodies yields anti-anti-idiotypic antibodies (Ab3), some of which can bind the antigen recognized by the original antibody (Ab1) (23-25). Preliminary experiments indicate that rabbits immunized with antibody 4E6 acquire MOR-h1 antibody activity in their sera (K. Essani and J. Satoh, unpublished observations).

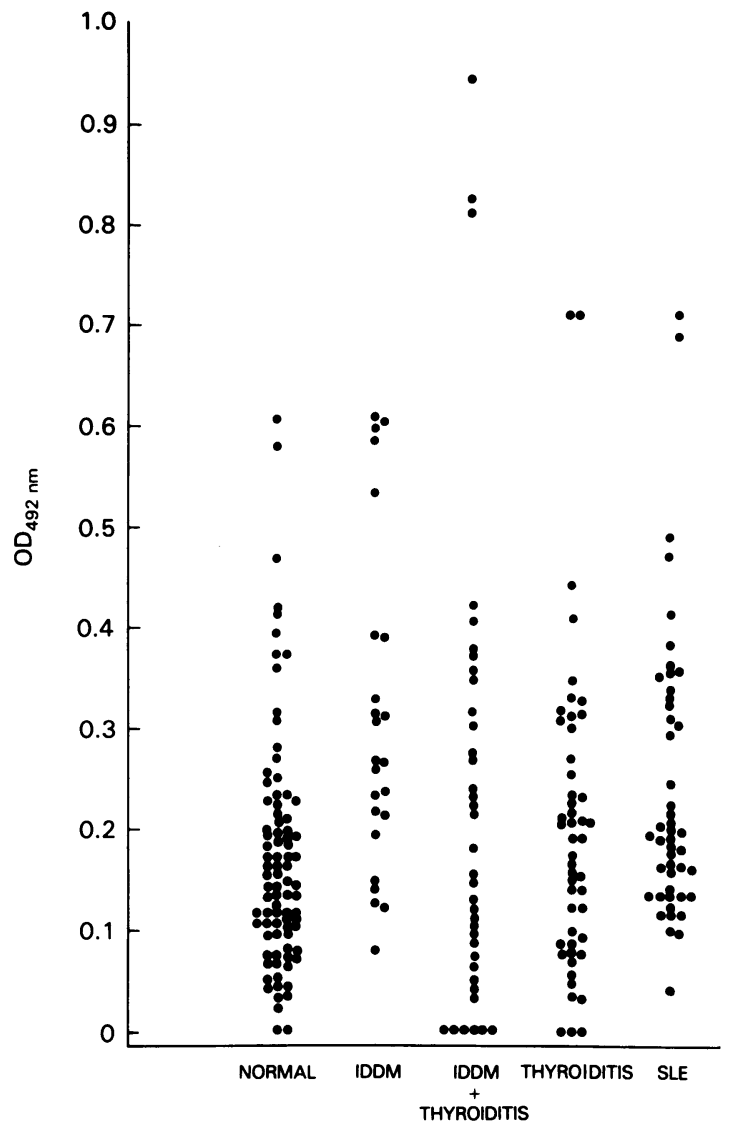

Figure 9. Detection of 4E6-idiotype-bearing IgG in sera from normal individuals and patients with autoimmune diseases. Blood was collected from patients with IDDM, IDDM and Hashimoto's thyroiditis, Hashimoto's thyroiditis alone, and SLE. The binding of immunoglobulin from each serum to either 4E6- or MOPC-21-coated plates was determined in an ELISA as described in Methods. The value plotted for each serum was calculated by subtracting the OD of the reaction with MOPC-21 from the OD of the reaction with 4E6. Each point represents an individual serum.

Having characterized the 4E6 anti-idiotypic antibody, we used it to study the expression of the 4E6 idiotope on human B lymphocytes. Our experiments revealed that the 4E6 idiotope is expressed on an average of $1.1 \%$ of normal B lymphocytes. This unexpectedly high frequency suggests that the 4E6 idiotope is expressed not only on B lymphocytes secreting MOR-h1 but also on lymphocytes with other specificities. Moreover, the majority of normal sera contained 4E6-idiotope bearing immunoglobulins in greater or lesser quantities. Despite the presence of the 4E6 idiotope, these sera did not possess MOR-h1-like antibody activity when tested against hGH, the 35,000-mol wt protein, or human tissues known to react with MOR-h1. In addition, in a competition assay, hGH failed to inhibit the binding of human sera to 4E6. Taken together, the data suggest that the 4E6 idiotope represents a public specificity on immunoglobulins and is not limited to just MOR-h1.

Our findings are consistent with the idea that idiotopes present on autoantibodies are not necessarily restricted to antibodies with the same antigen-binding specificity (26-28). In fact, antiidiotypic antibodies are known to cross-react with other immunoglobulins at sites not located at or near the antigen-binding domain $(29,30)$ and even at sites on nonimmunoglobulin mol- 
ecules (31). In this connection, Datta et al. (28) reported that normal mice without detectable amounts of anti-DNA antibody in their sera, expressed idiotopes that reacted with anti-idiotypic antibodies raised against anti-DNA antibodies. These idiotopes were expressed on both DNA-binding and non-DNA-binding immunoglobulins in the sera of normal mice. Anti-idiotypic antibodies (Ab2) also may recognize idiotopes on the parallel set of immunoglobulins (Ab3) which may not bind to the antigen that induces $\mathrm{Abl}$. In some cases, these idiotopes may be involved in immune regulation $(1,2)$.

It has been suggested that anti-idiotypic antibodies might serve as probes for detecting idiotopes that might be specifically expressed in certain autoimmune diseases $(28,32-35)$. It is clear, however, from both the present work and recent studies from other laboratories $(28,35)$ that idiotypic markers thought to be related to autoimmune diseases are expressed in normal individuals and that antibodies bearing these markers do not necessarily have the ability to bind autoantigens. This raises a number of fundamental questions about the clinical usefulness of anti-idiotypic antibodies as probes to study autoimmune diseases. First, do all patients with a specific autoimmune disease, or at risk of developing that disease, express the same idiotope? Second, is the specific monoclonal antibody used to make the antiidiotypic antibody present and active in the disease or is it simply part of the normal B cell repertoire (36)? Third, is the idiotope of interest expressed only on autoantibodies characteristic of that disease or is it more generally expressed and present on otherwise unrelated molecules? If the former, its expression may be easily quantitated and correlated with clinical disease activity. If the latter, the background reactivity may preclude meaningful quantitation. Perhaps some of these potential problems can be resolved, at least in part, by developing a large panel of antiidiotypic antibodies directed against a spectrum of disease-specific monoclonal autoantibodies.

\section{Acknowledgments}

We thank Dr. Fred Miller and Dr. Paul Plotz for providing sera from patients with systemic lupus erythematosus, Dr. Atsusi Muraguchi for helpful discussions concerning the immunostaining of B cells, and Ms. Denise Haller for the preparation of the manuscript.

\section{References}

1. Jerne, N. K. 1974. Towards a network theory of the immune system. Ann. Immunol. (Paris). 125C:373-389.

2. Paul, W. E., and C. Bona. 1982. Regulatory idiotopes and immune networks: a hypothesis. Immunol. Today. 3:230-234.

3. Wilson, D. B. 1984. Idiotypic regulation of self-reactive and alloreactive $\mathrm{T}$ cells in autoimmunity and graft-versus-host disease. Immunol. Today. 5:228-230.

4. Nydegger, U. E., K. Blaser, and A. Hässig. 1984. Antiidiotypic immunosuppression and its treatment with human immunoglobulin preparations. Vox Sang. 47:92-95.

5. Rauch, J., E. Murphy, J. B. Roths, B. D. Stollar, and R. S. Schwartz. 1982. A high frequency idiotypic marker of anti-DNA autoantibodies in MRL-lpr/lpr mice. J. Immunol. 129:236-241.

6. Matsuyama, T., J. Fukumori, and H. Tanaka. 1983. Evidence of unique idiotypic determinants and similar idiotypic determinants on human anti-thyroid antibodies. Clin. Exp. Immunol. 51:381-386.

7. Pons-Estel, B., F. Goni, A. Solomon, and B. Frangione. 1984. Sequence similarities among $\kappa$ IIIlb chains of monoclonal IgM $\kappa$ autoantibodies. J. Exp. Med. 160:893-904.

8. Satoh, J., B. S. Prabhakar, M. V. Haspel, F. Ginsberg-Fellner, and
A. L. Notkins. 1983. Human monoclonal autoantibodies that react with multiple endocrine organs. N. Engl. J. Med. 309:217-220.

9. Garzelli, C., F. E. Taub, J. E. Scharf, B. S. Prabhakar, F. GinsbergFellner, and A. L. Notkins. 1984. Epstein-Barr virus-transformed lymphocytes produce monoclonal autoantibodies that react with antigens in multiple organs. J. Virol. 52:722-725.

10. Satoh, J., K. Essani, P. R. McClintock, and A. L. Notkins. 1984. Human multiple organ-reactive monoclonal autoantibody recognizes growth hormone and a 35,000 molecular weight protein. J. Clin. Invest. 74:1526-1531.

11. Köhler, G., and C. Milstein. 1975. Continuous cultures of fused cells secreting antibody of predefined specificity. Nature (Lond.). 256: 495-497.

12. McKearn, T. J. 1980. Cloning of hybridoma cells by limiting dilution in fluid phase. In Monoclonal Antibodies: Hybridomas. A New Dimension in Biological Analyses R. H. Kennett, T. J. McKearn, and K. B. Bechtol, editors. Plenum Press, NY. 374.

13. Hunter, W. M., and F. C. Greenwood. 1962. Preparation of iodine 131-labelled human growth hormone of high specific activity. Nature (Lond.). 194:495-496.

14. Falkoff, R. M., M. Peters, and A. S. Fauci. 1982. T cell enrichment and depletion of human peripheral blood mononuclear cell preparations. Unexpected findings in the study of the functional activities of the separated populations. J. Immunol. Methods. 50:39-49.

15. Prabhakar, B. S., M. V. Haspel, P. R. McClintock, and A. L. Notkins. 1982. High frequency of antigenic variants among naturally occuring human coxsackie $\mathrm{B}_{\mathbf{4}}$ virus isolates identified by monoclonal antibodies. Nature (Lond.). 300:374-376.

16. Ju, S.-T., T. J. Kipps, J. Theze, B. Benacerraf, and M. E. Dorf. 1978. Idiotypic analysis of anti-GAT antibodies. I. Presence of common idiotypic specificities in both responder and non-responder mice. J. Immunol. 121:1034-1039.

17. Erlanger, B. F. 1985. Anti-idiotypic antibodies: what do they recognize? Immunol. Today. 6:10-11.

18. Cazenave, P.-A. 1977. Idiotypic-anti-idiotypic regulation of antibody synthesis in rabbits. Proc. Natl. Acad. Sci. USA. 74:5122-5125.

19. Urbain, J., M. Francotte, J. D. Franssen, J. Hiernaux, O. Leo, M. Moser, M. Slaoui, G. Urbain-Vansanten, A. Van Acker, and M. Wikler. 1983. From clonal selection to immune networks: induction of silent idiotypes. Ann. NY Acad. Sci. 418:1-8.

20. Sege, K., and P. A. Peterson. 1978. Use of anti-idiotypic antibodies as cell-surface receptor probes. Proc. Natl. Acad. Sci. USA. 75:24432447.

21. Nepom, J. T., H. L. Weiner, M-A. Dichter, M. Tardieu, D. R. Spriggs, C. F. Gramm, M. L. Powers, B. N. Fields, and M. I. Greene. 1982. Identification of a hemagglutinin-specific idiotype associated with Reovirus recognition shared by lymphoid and neural cells. J. Exp. Med. 155:155-167.

22. Lesniak, M. A., J. Roth, P. Gorden, and J. R. Gavin, III. 1972. Human growth hormone receptor assay using cultured human lymphocytes. Nature (Lond.). 241:20-22.

23. Urbain, J., M. Wikler, J. D. Franssen, and C. Collignon. 1977. Idiotypic regulation of the immune system by the induction of antibodies against anti-idiotypic antibodies. Proc. Natl. Acad. Sci. USA. 74:51265130.

24. Reagan, K. J., W. H. Wunner, T. J. Wiktor, and H. Koprowski. 1983. Anti-idiotypic antibodies induce neutralizing antibodies to Rabies virus glycoprotein. J. Virol. 48:660-666.

25. Kennedy, R. C., and G. R. Dreesman. 1984. Enhancement of the immune response to hepatitis $B$ surface antigen: in vivo administration of anti-idiotype induces anti-HBs which expresses a similar idiotype. $J$. Exp. Med. 159:655-665.

26. Oudin, J., and P. A. Cazenave. 1971. Similar idiotype specificities in immunoglobulin fractions with different antibody functions or even without detectable antibody function. Proc. Natl. Acad. Sci. USA. 68: 2616-2620.

27. Pisetsky, D. S., K. F. Semper, and R. A. Eisenberg. 1984. Idiotypic 
analysis of a monoclonal anti-Sm antibody. II. Strain distribution of a common idiotypic determinant and its relationship to anti-Sm expression. J. Immunol. 133:2085-2089.

28. Datta, S. K., B. D. Stollar, and R. S. Schwartz. 1983. Normal mice express idiotypes related to autoantibody idiotypes of lupus mice. Proc. Natl. Acad. Sci. USA. 80:2723-2727.

29. Goldberg, B., W. E. Paul, and C. Bona. 1983. Idiotype-antiidiotype regulation. IV. Expression of common regulatory idiotypes on fructosanbinding and non-fructosan-binding monoclonal immunoglobulin. J. Exp. Med. 158:515-528.

30. Bona, C. A., B. Goldberg, D. Metzger, J. Urbain, and H. G. Kunkel. 1984. Anti-immunoglobulin antibodies. IV. Cross-reaction of anti-idiotypic antibodies specific for rabbit and murine anti- $a_{1}$ allotype antibodies with Fc fragment of human immunoglobulins. Eur. J. Immunol. 14:548-552.

31. Bona, C., S. Finley, S. Waters, and H. G. Kunkel. 1982. Antiimmunoglobulin antibodies. III. Properties of sequential anti-idiotype antibodies to heterologous anti- $\gamma$-globulins. Detection of reactivity of antibodies with epitopes of $\mathrm{Fc}$ fragments (homobodies) and with epitopes and idiotopes (epibodies). J. Exp. Med. 156:986-999.
32. Delves, P. J., and I. M. Roitt. 1984. Idiotypic determinants on human thyroglobulin autoantibodies derived from the serum of Hashimoto patients and EB virus transformed cell lines. Clin. Exp. Immunol. 57:33-40.

33. Ledford, D. K., F. Goni, M. Pizzolato, E. C. Franklin, A. Solomon, and B. Frangione. 1983. Preferential association of $k$ IIIlb light chains with monoclonal human IgM $\kappa$ autoantibodies. J. Immunol. 131:13221325.

34. Solomon, G., J. Schiffenbauer, H. D. Keiser, and B. Diamond. 1983. Use of monoclonal antibodies to identify shared idiotypes on human antibodies to native DNA from patients with the systemic lupus erythematosus. Proc. Natl. Acad. Sci. USA. 80:850-854.

35. Isenberg, D. A., Y. Shoenfeld, M. Madaio, J. Rauch, M. Reichlin, B. D. Stollar, and R. S. Schwartz. 1984. Anti-DNA antibody idiotypes in systemic lupus erythematosus. Lancet. II:417-422.

36. Prabhakar, B. S., J. Saegusa, T. Onodera, and A. L. Notkins. 1984. Lymphocytes capable of making monoclonal autoantibodies that react with multiple organs are a common feature of the normal B cell repertoire. J. Immunol. 133:2815-2817. 